\title{
Determination of Perfluorinated Compounds in Human Blood Samples by High Performance Liquid Chromatography- Electrospray Tandem Mass Spectrometry
}

\author{
PAN Yuan-Yuan, SHI Ya-Li, CAI Ya-Qi*
}

State Key Laboratory of Environmental Chemistry and Ecotoxicology, Research Center for Eco-Environmental Science, Chinese Academy of Sciences, Beijing 100085, China

\begin{abstract}
Perfluorinated compounds (PFCs) in human whole blood samples, i.e., perfluorohexane sulfonate (PFHxS), perfluoroheptanoic acid (PFHpA), perfluorooctanoate (PFOA), perfluorooctane sulfonate (PFOS), perfluorononanoic acid (PFNA), perluorodecanoic acid (PFDA), perfluoroundecanoic acid (PFUnDA), perfluorododecanoic acid (PFDoDA) and perfluorotetradecanoic acid (PFTA) were detected and separated by High performance Liquid chromatography/electrospray tandem mass spectrometry (HPLC-ESI-MS/MS) with $\mathrm{C}_{18}$ reversed-phase column, and ${ }^{13} \mathrm{C}_{4}$-labeled PFOS (MPFOS) as the internal standard in $15 \mathrm{~min}$. PFCs in the blood samples were further extracted with solid phase extraction cartridges after traditional MTBE extraction before analysis. Four kinds of cartridges were tested for their capabilities of PFCs adsorption, including RP, P, $\mathrm{C}_{18}$ and HLB, and then HLB cartridge was selected for its efficiency of PFCs extraction. A comparative study of two $\mathrm{C}_{18}$ columns, Acclaim $120(50 \mathrm{~mm} \times 4.6$ $\mathrm{mm}, 3 \mu \mathrm{m})$ and Acclaim $120(250 \mathrm{~mm} \times 4.6 \mathrm{~mm}, 5 \mu \mathrm{m})$ columns were also performed. Both the columns provided similar sensitivities and good separation, with the detection limits $0.01-0.20 \mu \mathrm{g}^{-1}$ for real blood samples. The relative standard deviation of peak area ranged from $3 \%$ to $11 \%$. Acclaim $120(250 \mathrm{~mm} \times 4.6 \mathrm{~mm}, 5 \mu \mathrm{m})$ column was chosen for its superior in column capacity. Under the optimal conditions, the recoveries of PFCs in blood samples ranged $80 \%-118 \%$, with the exception of PFTA, the recovery of which was only about $60 \%$.
\end{abstract}

Key Words: Perfluorinated compounds (PFCs); High performance liquid chromatography-electrospray tandem mass spectrometry; Human blood

\section{Introduction}

Perfluorinated compounds (PFCs) have been recognized as widespread contaminants in the environment. PFCs are chemically and physically stable due to the strong carbon-fluorine $(\mathrm{C}-\mathrm{F})$ covalent bonds, so these compounds are still manufactured and used in a wide range of industrial and consumer applications, such as textiles, package, upholstery, surface treatment, as well as firefighting foams and personal care products ${ }^{[1-3]}$. Since perfluorinated sulfonic and carboxylic acids are expected to be resistant to hydrolysis, photolysis and metabolic degradation, PFCs tend to be persistent in environment ${ }^{[1]}$. To date, there have been many reports on the occurrence of PFCs in water ${ }^{[4,5]}$, sludge ${ }^{[6]}$, and many biological matrices ${ }^{[7,8]}$, even in human blood and serum $^{[9]}$. PFCs are attracting increased attention due to their accumulation in human and wildlife as well as the potential toxicity $^{[10]}$. Perfluorooctane sulfonate (PFOS) and perfluorooctanoate (PFOA) have been found to be the representative PFCs in the environment and in biota ${ }^{[11,12]}$, and PFOS is regarded as the final metabolite of many PFCs by degradation or metabolization ${ }^{[13]}$. Differences between both sexes in the concentrations of PFOS, PFOA and related fluorochemicals have been found in human blood, but no

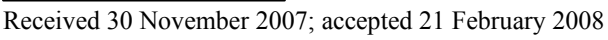

* Corresponding author. Email: caiyaqi@rcees.ac.cn

This work was supported by the grants from the State High Tech Development Plan of China (No. 2007AA06Z405), Research Program of Chinese Academy of Sciences of China (No. KZCX2-YW-420-1) and the National Basic Research Program of China (No. 2003CB415001).

Copyright (C) 2008, Changchun Institute of Applied Chemistry, Chinese Academy of Sciences. Published by Elsevier Limited. All rights reserved. 
age-related difference has been observed until now ${ }^{[14]}$. The study of PFCs has become a hot spot in environmental science and ecotoxicological research, but our domestic research is just the beginning and relative reports are scare. Thus, it will be significative if a sensitive and applicable method for the separation and determination of PFCs is established.

In this study, a reliable and sensitive method for the trace level analysis of perfluorinated compounds in human whole blood samples was established. Using high performance Liquid chromatography/electrospray tandem mass spectrometry (HPLC-ESI-MS/MS), nine PFCs were identified and quantified in two blood samples. PFCs were extracted and purified by means of ion-pair liquid-liquid extraction method combined with SPE extraction, and then separated on $\mathrm{C}_{18}$ reversed-phase column. A comparative study of two $\mathrm{C}_{18}$ columns from Dionex, Acclaim $120(50 \mathrm{~mm} \times 4.6 \mathrm{~mm}, 3 \mu \mathrm{m})$ and Acclaim $120(250 \mathrm{~mm} \times 4.6 \mathrm{~mm}, 5 \mu \mathrm{m})$ columns were performed. Moreover, the capabilities of four SPE cartridges were also discussed. Under the optimal conditions, PFCs in real blood samples were detected and the recoveries of PFCs in blood samples ranged $80 \%-118 \%$, with the exception of PFTA, the recovery of which was only about $60 \%$.

\section{Experimental}

\subsection{Instruments and reagents}

A HPLC apparatus was a Dionex HPLC system (Sunnyvale, CA, USA), composed of a P680 pump, a Ultimate 3000 autosampler and Chromeleon 6.70 software. Separation was accomplished on Dionex $\mathrm{C}_{18}$ column, Acclaim $120(50 \mathrm{~mm} \times 4.6 \mathrm{~mm}, 3 \mu \mathrm{m})$ and Acclaim 120 $(250 \mathrm{~mm} \times 4.6 \mathrm{~mm}, 5 \mu \mathrm{m})$. Mass spectrometry was a tandem mass spectrometer system (MS/MS) (API 3200; Applied Biosystems/MDS SCIEX, US) with electrospray ionization (ESI) and Analyst 1.4.2 software.

Nine perfluorinated compounds were examined in this study. Perfluorohexane sulfonate (PFHxS), perfluorohep-
Table 1 Gradient condition of eluent

\begin{tabular}{cccc}
\hline \multirow{2}{*}{$\begin{array}{c}\text { Time } \\
\text { min })\end{array}$} & \multicolumn{2}{c}{ Acclaim $120 \mathrm{C}_{18}$ Percentage of $\mathrm{E}_{\mathrm{B}}(\%)$} & \\
\cline { 2 - 3 } 0.0 & 40 & $250 \mathrm{~mm} \times 4.6 \mathrm{~mm}, 5 \mu \mathrm{m}$ & \\
\hline 0.1 & 40 & 28 & \\
6.0 & 5 & 28 & 5 \\
9.5 & 5 & 5 & 5 \\
9.6 & 40 & 5 & 5 \\
15.0 & 40 & 28 & 5 \\
\hline
\end{tabular}

* Curve 5 is linear gradient.

tanoic acid (PFHpA), PFOA, perfluorononanoic acid (PFNA), perluorodecanoic acid (PFDA), perfluoroundecanoic acid (PFUnDA), perfluorododecanoic acid (PFDoDA), perfluorotetradecanoic acid (PFTA), tetra-n-butylammonium hydrogen sulfate (TBA) and ammonium acetate $\left(\mathrm{NH}_{4} \mathrm{OAc}\right)$ were all purchased from Alfa Aesar; PFOS was purchased from Sigma-Aldrich (Oakville, ON, Canada); ${ }^{13} \mathrm{C}_{4}$-PFOS( MPFOS ) was purchased from Wellington Laboratories (Canada) as the internal standard, and methyl-tert-buty ether (MTBE) was obtained from Acros; $\mathrm{CH}_{3} \mathrm{OH}$ was of optimal grade (Fisher Scientific, Pittsburgh, PA).

Mill-Q water was prepared on a Milli-Q Advantage A10 system (Millipore, USA) with a specific resistance of 18.2 $\mathrm{M} \Omega \cdot \mathrm{cm}^{-1}$.

\subsection{Conditions of HPLC and MS}

Compounds were separated on $\mathrm{C}_{18}$ column via the elution of a dualistic gradient of $\mathrm{CH}_{3} \mathrm{OH}\left(\mathrm{E}_{\mathrm{A}}\right)$ and $2 \mathrm{mM} \mathrm{N \textrm {N } _ { 4 } \mathrm { OAc }}$

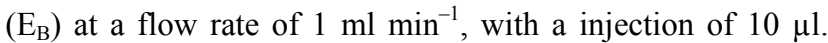
The gradient conditions for the two columns are listed in Table 1.

PFCs were detected under multiple reactions monitoring (MRM) mode. The ESI source was operated in negative-ion, with the ion spray voltage (IS) and temperature (TEM) kept at $-4500 \mathrm{~V}$ and $500{ }^{\circ} \mathrm{C}$ respectively. The curtain gas, collision gas, ion sources Gas1 and Gas2 were 0.10, 0.21, 0.38 and $0.34 \mathrm{MPa}$, respectively. The detail detect conditions of PFCs are shown in Table 2.

Table 2 Experimental conditions of electrospray tandem mass spectrometry

\begin{tabular}{|c|c|c|c|c|c|c|c|c|}
\hline & $\begin{array}{l}\text { Parent } \\
\text { ion Q1 }\end{array}$ & $\begin{array}{c}\text { Daughter } \\
\text { ion Q3 }\end{array}$ & $\begin{array}{l}\text { Time } \\
\text { (ms) }\end{array}$ & $\begin{array}{l}\text { Declustering } \\
\text { potential }(\mathrm{V})\end{array}$ & $\begin{array}{c}\text { Entrance } \\
\text { potential }(\mathrm{V})\end{array}$ & $\begin{array}{c}\text { Collision cell ent. } \\
\text { potential (V) }\end{array}$ & $\begin{array}{l}\text { Collision energy } \\
\text { (V) }\end{array}$ & $\begin{array}{c}\text { Collision cell exit } \\
\text { potential (V) }\end{array}$ \\
\hline PFHxS & 398.7 & 79.9 & 50 & -65 & -7.0 & -16.93 & -70 & -3.0 \\
\hline PFHpA & 362.9 & 319.0 & 50 & -23 & -4.0 & -12.61 & -13 & -4.0 \\
\hline PFOA & 412.8 & 369.0 & 50 & -23 & -4.0 & -15.45 & -16 & -5.0 \\
\hline PFOS & 498.8 & 79.9 .0 & 50 & -75 & -6.0 & -13.64 & -90 & -3.0 \\
\hline PFNA & 462.8 & 419.0 & 50 & -22 & -3.0 & -13.30 & -15 & -6.5 \\
\hline PFDA & 512.8 & 469.0 & 50 & -20 & -4.5 & -50.15 & -20 & -14.0 \\
\hline PFUnDA & 562.9 & 519.0 & 50 & -27 & -4.5 & -20.01 & -23 & -15.0 \\
\hline PFDoDA & 613.0 & 569.0 & 50 & -28 & -4.5 & -21.86 & -18 & -17.0 \\
\hline PFTA & 713.0 & 669.0 & 50 & -27 & -4.5 & -21.56 & -19 & -21.0 \\
\hline MPFOS & 502.9 & 80.0 & 50 & -75 & -7.5 & -17.79 & -90 & -5.0 \\
\hline
\end{tabular}




\subsection{Sample preparation and extraction}

Samples of whole blood were kept at $-20{ }^{\circ} \mathrm{C}$ before pretreatment. Standard mixtures for quality control, including 9 analyses, and samples were all prepared and processed via the same procedure, that was, ion-pair liquid-liquid extraction method which was described elsewhere ${ }^{[12]}$, followed by SPE preparation. Only polypropylene (PP) tubes were adopted during the process.

In brief, blood samples were thawed at room temperature before extraction. Whole blood of $0.5 \mathrm{ml}$ was adjusted to $1 \mathrm{ml}$ with water in a $15 \mathrm{ml} \mathrm{PP}$ tube (containing $5 \mathrm{ng}$ internal standard). Then $1 \mathrm{ml}$ of TBA and $2 \mathrm{ml}$ of sodium carbonate (pH 10) were added to it. After mixing thoroughly, $5 \mathrm{ml}$ of MTBE was added to the mixture, and the mixture was shaken for $20 \mathrm{~min}$ at $250 \mathrm{rpm}$ and centrifuged at $3000 \mathrm{rpm}$ for $15 \mathrm{~min}$. Then, $4 \mathrm{ml}$ of MTBE supernatant was taken out and transferred to another $15 \mathrm{ml} \mathrm{PP}$ tube. The procedure was repeated twice as mentioned above except that $5 \mathrm{ml}$ of MTBE was collected each time. All the three extracts were combined, and the final extract was concentrated to $0.5 \mathrm{ml}$ under nitrogen gas after adding $1 \mathrm{ml}$ of methanol. Finally the condensed extraction was diluted with $100 \mathrm{ml}$ deionized water prior to solid phase extraction cleanup. The dilution was loaded onto the preconditioned SPE cartridge at a flow rate of 1 drop s$^{-1}$ with a positive pressure pump. The cartridge was then washed and the target analyses were eluted from the cartridge with $10 \mathrm{ml}$ of methanol at a flow rate of 1 drop s${ }^{-1}$. The eluate was reduced to $1 \mathrm{ml}$ with nitrogen before injection.

The precondition and extraction procedures for four kinds of SPE cartridges are little different. P (1 cc) and RP (1 cc) cartridges were products of Dionex (USA); P cartridge was preconditioned with $10 \mathrm{ml}$ of water and RP cartridge was preconditioned with $5 \mathrm{ml}$ of methanol and $10 \mathrm{ml}$ of water before using. $\mathrm{C}_{18}$ cartridge was purchased from Tianjin Fuji Science and Technology Corporation, it was conditioned with $5 \mathrm{ml}$ of methanol and $10 \mathrm{ml}$ of water before extraction, and after sample loaded the cartridge was washed with $5 \mathrm{ml}$ of $20 \%$ methanol in water.

Oasis ${ }^{\circledR}$ HLB (200 mg, $6 \mathrm{cc}$ ) cartridges were obtained from Waters (USA), and the preconditioned with $5 \mathrm{ml}$ of methanol and $5 \mathrm{ml}$ of water at a flow rate of 2 drop $\mathrm{s}^{-1}$. After sample loaded, the cartridge was washed with $5 \mathrm{ml}$ of $40 \%$ methanol in water at a flow rate of 1 drop s $\mathrm{s}^{-1}$, then the cartridge was centrifuged at $3000 \mathrm{rpm}$ for $2 \mathrm{~min}$ to remove water remained.

\section{Results and discussion}

\subsection{HPLC-MS/MS conditions}

Because PFCs are both hydrophobic and oleophobic organic compounds with polarity, the $\mathrm{C}_{18}$ reversed-phase columns with low silanol activity were selected for their separation. Since the target analyses are perfluorinated sulfonates or carboxylic acids, the ion-pair reagent and $\mathrm{pH}$ value in eluent will obviously affect the separation of PFCs on $\mathrm{C}_{18}$ columns, in present study, $\mathrm{NH}_{4} \mathrm{OAc}$ was added in the gradient eluentto regulate ionic strength and $\mathrm{pH}$ value. With a dualistic gradient eluent of methanol and $2 \mathrm{mM} \mathrm{NH} \mathrm{mHAc}_{4} \mathrm{O}$ (Table 1), the separation of nine analyses was conducted only within $15 \mathrm{~min}$.

The condition of MS/MS was manually determined under the tune mode with a syringe pump. Firstly Q1 and Q3 were optimized to fix the parent and daughter ions, and then other parameters were optimized (Table 2).

All accessible polytetrafluorethylene (PTFE) materials were removed from the instruments and apparatus to minimize background signal due to contamination. In the chromatogram system, stainless steel and PEEK pipeline were employed all through the experiment.

\subsection{Development of pretreatment method}

The most commonly used method for blood sample is liquid-liquid extraction with $\mathrm{MTBE}^{[12]}$, however, some proteins and other interferences can not be removed completely only by liquid extraction, and these impurities will severely affect the detection sensitivity and reduce the useful life of column. Therefore, further purification will be necessary.

Unlike the traditional MTBE extraction method, PFCs in the blood samples were further extracted with solid phase extraction cartridges before detected by HPLC/MS/MS, and four SPE cartridges were examined for their capabilities, including RP, P, $\mathrm{C}_{18}$ and HLB. Four aliquots of $1 \mu \mathrm{g} 1^{-1}$ standard mixtures (spiked with $5 \mathrm{ng}$ internal standard) were diluted in water and loaded onto SPE cartridges. It was found that neither RP nor $\mathrm{P}$ cartridge was adaptable. PFCs performed poor adsorption on $\mathrm{P}$ cartridge except PFOS and PFUnDA, and analyses with long chains could not be easily eluted from RP cartridge, such as PFUnDA, PFDoDA and PFTA, and the recoveries turned poorer as the length increase of carbochain, only $88 \%, 74 \%$ and $39 \%$, respectively. Satisfactory recoveries were achieved on $\mathrm{C}_{18}$ and HLB. As 1 $\mu \mathrm{g} \mathrm{l}^{-1}$ PFCs standards (spiked with $5 \mathrm{ng}$ internal standard) were treated with the same procedure as blood samples, all the analyses were well recovered, with recoveries for 9 PFCs $88.2 \%-123 \%$ and $89.5 \%-123 \%$, respectively. However, when $\mathrm{C}_{18}$ cartridge was applied to real blood samples, PFHxS, PFHpA and PFOA were hardly recovered, the reason was not known yet. Other analyses can be well recovered except PFTA (only $40 \%$ ), with the recoveries ranging from $91.6 \%$ to $120 \%$. Finally HLB cartridge was selected for its efficient extraction of these compounds from the sample matrix. 


\subsection{Method precision and accuracy}

Under the optimal chromatographic and MS/MS conditions, $10 \mu \mathrm{l}$ of standards solutions (9 analyses spiked with $5 \mathrm{ng}$ internal standard) were injected on $\mathrm{C}_{18}$ columns, and the results of regression equations and correlation coefficient are listed in Tables 3 and 4, respectively.

Both $\mathrm{C}_{18}$ columns provided similar sensitivities, with the detection limits $(S / N=3) 0.03-0.8 \mu \mathrm{g} \mathrm{l}^{-1}$, and their linear ranges were $0.1-50 \mu \mathrm{g} \mathrm{I}^{-1}$ and $0.05-50 \mu \mathrm{g}^{-1}$, respectively. The relative standard deviation of peak area ranged from $3 \%$ to $11 \%$, indicating good method precision and that both columns were appropriate for PFCs analysis.

However, considering the possible interferences in the extractions of samples with complicated matrices, we chose Acclaim $120(250 \mathrm{~mm} \times 4.6 \mathrm{~mm}, 5 \mu \mathrm{m})$ with larger capacity as the analytical column.

\subsection{Concentrations of PFCs in blood samples}

PFOS and PFOA have been found to be the major PFCs in the environment, concentrations of which are much greater than those of any other PFCs, especially PFOS ${ }^{[11,12]}$. The similar results (Tables 5 and 6) were obtained. PFOS and PFOA were detected in both the blood samples, and PFOS accounted for $26 \%$ and $87 \%$ of gross. The spiked recoveries were determined on the basis of each PFCs' concentration; the recoveries of detected PFCs were $74.2 \%-107.2 \%$ and $89.4 \%-118.1 \%$ for samples $1^{\#}$ and $2^{\#}$, respectively. However, the recoveries of PFTA were relatively lower, only $57.3 \%$ and $71.7 \%$ for both the samples. Figure 1 shows the chromatograms of blood sample $1^{\#}$ along with the spiked one. From the chromatograms, we can find there are two peaks for PFOS, which is because there are two isomers for PFOS, linear chain and branched chain, which was reported by Calafat ${ }^{[15]}$. In this study, the quantification was based on the sum area of the two peaks.

Table 3 Regression equations and correlation coefficients for Acclaim $120(50 \mathrm{~mm} \times 4.6 \mathrm{~mm}, 3 \mu \mathrm{m})$

\begin{tabular}{|c|c|c|c|c|c|}
\hline Analyses & Regression Equation $^{*}$ & Correction coefficient $(r)$ & LODs $\left(\mu \mathrm{g}^{-1}\right)$ & Linear range $\left(\mu \mathrm{g}^{-1}\right)$ & $\operatorname{RSD}(n=10)$ \\
\hline PFHxS & $y=0.179 x-1.83 \times 10^{-3}$ & 0.9987 & 0.06 & $0.1-50$ & $3.3 \%$ \\
\hline PFHpA & $y=0.0623 x+2.48 \times 10^{-3}$ & 0.9986 & 0.80 & $1.0-50$ & $7.1 \%$ \\
\hline PFOA & $y=0.0709 x-1.62 \times 10^{-3}$ & 0.9977 & 0.60 & $1.0-50$ & $9.0 \%$ \\
\hline PFOS & $y=0.169 x+2.50 \times 10^{-3}$ & 0.9986 & 0.08 & $0.1-50$ & $4.5 \%$ \\
\hline PFNA & $y=0.0513 x+8.19 \times 10^{-3}$ & 0.9990 & 0.60 & $1.0-50$ & $7.4 \%$ \\
\hline PFDA & $y=0.0165 x-1.72 \times 10^{-3}$ & 0.9994 & 0.20 & $0.5-50$ & $10.1 \%$ \\
\hline PFUnDA & $y=0.0291 x+3.64 \times 10^{-3}$ & 0.9970 & 0.40 & $0.5-50$ & $6.2 \%$ \\
\hline PFDoDA & $y=0.0311 x+2.00 \times 10^{-3}$ & 0.9985 & 0.24 & $0.5-50$ & $8.4 \%$ \\
\hline PFTA & $y=0.0179 x+1.92 \times 10^{-3}$ & 0.9985 & 0.24 & $0.5-50$ & $8.6 \%$ \\
\hline
\end{tabular}

*: $x$ is content, $\mu \mathrm{g} / \mathrm{L} ; y$ is the ratio of peak area between analyses and internal standard

Table 4 Regression equations and correlation coefficients for Acclaim $120(250 \mathrm{~mm} \times 4.6 \mathrm{~mm}, 5 \mu \mathrm{m})$

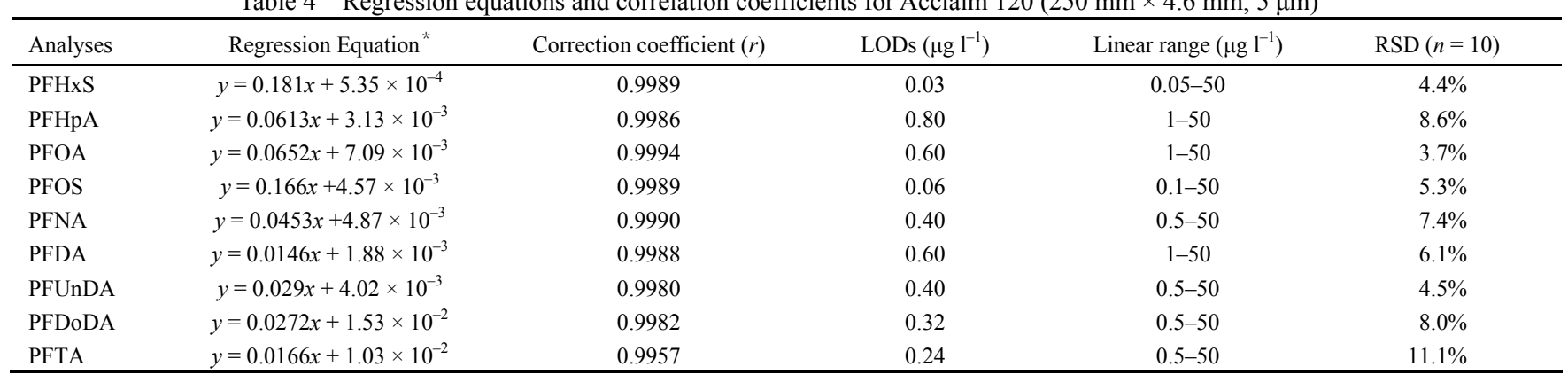

*: $x$ is content, $\mu \mathrm{g} 1^{-1} ; y$ is the ratio of peak area between analyses and internal standard

Table 5 Results of PFCs in blood samples $1^{\#}$

\begin{tabular}{|c|c|c|c|c|c|}
\hline \multirow{2}{*}{ Compounds } & \multirow{2}{*}{$\begin{array}{l}\text { Contents in sample } \\
\left(\mu \mathrm{g} \mathrm{l}^{-1}\right)\end{array}$} & \multicolumn{4}{|c|}{ Recoveries } \\
\hline & & Found $\left(\mu \mathrm{g} 1^{-1}\right)$ & Added $\left(\mu g \mathrm{I}^{-1}\right)$ & Found after spiked $\left(\mu \mathrm{g}^{-1}\right)$ & Recovery $(\%)$ \\
\hline PFHxS & 0.15 & 0.075 & 0.5 & 0.54 & 93.0 \\
\hline PFHpA & 0.38 & 0.19 & 0.5 & 0.63 & 89.8 \\
\hline PFOA & 0.76 & 0.38 & 0.5 & 0.90 & 104.3 \\
\hline PFOS & 1.64 & 0.82 & 1.0 & 1.72 & 89.4 \\
\hline PFNA & 1.00 & 0.50 & 0.5 & 1.02 & 104.5 \\
\hline PFDA & 0.52 & 0.26 & 0.5 & 0.85 & 118.1 \\
\hline PFUnDA & 0.72 & 0.36 & 0.5 & 0.85 & 96.6 \\
\hline PFDoDA & ND & ND & 0.5 & 0.52 & 104.5 \\
\hline PFTA & ND & ND & 0.5 & 0.29 & 57.3 \\
\hline
\end{tabular}

ND: not detected. 
Table 6 Results of PFCs in blood samples $2^{\#}$

\begin{tabular}{|c|c|c|c|c|c|}
\hline \multirow{2}{*}{ Compounds } & \multirow{2}{*}{$\begin{array}{c}\text { Contents in sample } \\
\qquad\left(\mu \mathrm{g} \mathrm{l}^{-1}\right)\end{array}$} & \multicolumn{4}{|c|}{ Recovery } \\
\hline & & Found $\left(\mu \mathrm{g}^{-1}\right)$ & Added $\left(\mu \mathrm{g}^{-1}\right)$ & Found after spiked $\left(\mu \mathrm{g}^{-1}\right)$ & Recovery $(\%)$ \\
\hline PFHxS & 1.06 & 0.53 & 0.5 & 0.96 & 85.2 \\
\hline PFHpA & 0.46 & 0.23 & 0.5 & 0.67 & 87.3 \\
\hline PFOA & 1.38 & 0.69 & 0.5 & 1.13 & 86.0 \\
\hline PFOS & 30.2 & 15.1 & 15.5 & 27.6 & 80.6 \\
\hline PFNA & 0.74 & 0.37 & 0.5 & 0.74 & 74.2 \\
\hline PFDA & 0.56 & 0.28 & 0.5 & 0.77 & 97.9 \\
\hline PFUnDA & 0.28 & 0.14 & 0.5 & 0.73 & 116.7 \\
\hline PFDoDA & ND & ND & 0.5 & 0.54 & 107.2 \\
\hline PFTA & ND & ND & 0.5 & 0.36 & 71.7 \\
\hline
\end{tabular}

ND: not detected
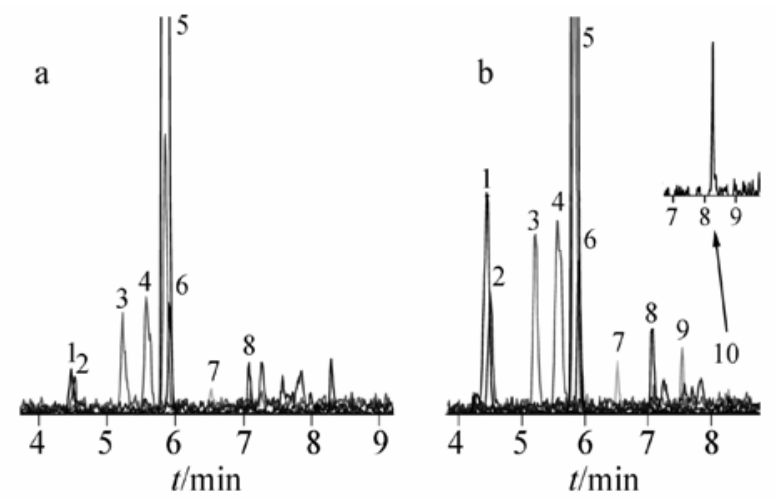

Fig.1 Chromatograms of blood sample 1

1. PFHxS; 2. PFHpA; 3.PFOA; 4. PFOS; 5. MPFOS; 6. PFNA; 6. PFDA; 7. PFUnDA; 8. PFDoDA; 10.PFTA

\section{Conclusions}

The method for the determination of perfluorinated compounds in blood samples, that is High performance liquid chromatography/electrospray tandem mass spectrometry (HPLC-ESI-MS/MS) has been established, and the determination of 9 analyses can be accomplished within $15 \mathrm{~min}$. The method was sensitive and credible, and can be applied to samples with complicated matrices such as blood. PFCs in two randomly collected human whole blood samples were analyzed. It is concluded that trace levels of PFCs do exist in human beings, of which PFOS and PFOA are dominant.

\section{Acknowledgement}

We greatly acknowledge Li Xue-Mei from Institute of Zoology Chinese Academy of Sciences for her volunteer assistance and help for this study.

\section{References}

[1] Tseng C L, Liu L L, Chen C M, Ding W H. J. Chromatogr. A, 2006, 1105: 119-126

[2] So M K, Yamashita N, Taniyasu S, Jiang Q T, Giesy J P, Chen K, Lam P K S. Environ. Sci. Technol., 2006, 40: 2924-2929

[3] Giesy J P, Kannan K. Environ. Sci. Technol., 2002, 36: $146 \mathrm{~A}-152 \mathrm{~A}$

[4] Moody C A, Martin J W, Kwan W C, Muir D C, Mabury S C. Environ. Sci. Technol., 2002, 36: 545-551

[5] Zhang P, Shi Y L, Cai Y Q, Mou S F. Chinese J. Anal. Chem., 2007, 35(7): 969-972

[6] Higgins C P, Mcleod P B, Macmanus-Spencer L A, Luthyric R G. Environ. Sci. Technol., 2007, 41: 4600-4606

[7] Kannan K, Yun S H, Evans T J. Environ. Sci. Technol., 2005, 39: 9057-9063

[8] Taniyasu S, Kannan K, Horii Y, Hanari N, Yamashita N. Environ. Sci. Technol., 2003, 37: 1634-2639

[9] Jonathan P B, Mahmoud B, Jonathan W M. Anal. Chem., 2007, 79: 6455-6464

[10] U. S. Evironmental Protection Agency. Fed. Reg., 2001, 65: 62319-62333

[11] Guruge K S, Taniyasu S, Yamashita N, Wijeratna S, Mohotti K M, Seneviratne H R, Kannan K, Miyazaki S. J. Environ. Monit., 2005, 7: 371-377

[12] Kannan K, Corsolini S, Falandysz J, Fillmann G, Kumar K S, Loganathan B G, Mohd M A, Olivero J, Van Wouwe N, Yang J H, Aldous K M. Environ. Sci. Technol., 2004, 38: 4489-4495

[13] Olsen G W, Burris J M, Mandel J H, Zobel L R. J. Occup. Environ. Med., 1999, 41: 799-806

[14] Calafat A M, Kuklenyik Z, Caudill S P, Reidy J A, Needham L L. Environ. Health Perspect., 2003, 111: 1892-1901

[15] Kuklenyik Z, Reich J A, Tully J S, Needham L L, Calafat A M. Environ. Sci. Technol., 2004, 38: 3698-3704 